\title{
PARIWISATA KREATIF DAN KEGIATAN EKSTRAKURIKULER BERBASIS BAMBU DALAM PENGEMBANGAN MODEL BISNIS CV SURATIN BAMBOO
}

\author{
Dewa Ayu Tenara Kardinia Cidhy $^{*) 1}$, Lukman M. Baga**), dan Setiadi Djohar ${ }^{* * *}$ \\ *) Sekolah Bisnis, Institut Pertanian Bogor \\ Jl. Meranti Wing 22 level 4-5, Kampus IPB Darmaga 16680 \\ **) Departemen Agribisnis, Fakultas Ekonomi dan Manajemen, Institut Pertanian Bogor \\ Kampus IPB Dramaga PO. Box 220 Bogor 16002 \\ ${ }^{* * *}$ Sekolah Tinggi Manajemen PPM \\ Jl. Menteng Raya 9-19, Jakarta 10340
}

\begin{abstract}
The objective of this study was to design a prototype of a future business model which would be adopted to achieve balance between the aspects of new business opportunities and competitive advantages of CV Suratin Bamboo. The analytical method utilized in the study was the business model canvas approach (BMC) supported by the blue ocean strategy and SWOT. The results revealed that through this business model development, bamboo workshop is expected to provide information regarding bamboo derived products, raise awareness of preserving the indigenous bamboo culture, increase sense of belonging to domestic products, as well as become the primary support of innovation and ideas in constructing Indonesia as a nation. Meanwhile, for businesses actors, besides increasing revenue, conducting bamboo workshops is expected to increase the company growths for the long term. The opportunity to maneuver in the development of bamboobased business model demonstrates that bamboo business with high quality products has both tangible and intangible potentials to be developed further.
\end{abstract}

Keywords: bamboo, blue ocean strategy, business model canvas, creative tourism, extracurricular

\begin{abstract}
ABSTRAK
Tujuan penelitian ini adalah merancang prototype model bisnis masa depan yang akan digunakan untuk menemukan keseimbangan antara aspek peluang bisnis yang baru dan aspek keuntungan kompetitif CV Suratin Bamboo. Metode analisis yang digunakan adalah dengan pendekatan kanvas model bisnis (BMC) dilengkapi dengan blue ocean strategy serta SWOT. Hasil penelitian menunjukkan melalui pengembangan model bisnis ini, pelatihan bambu diharapkan mampu memberikan informasi tentang produk turunan bambu, meningkatkan kesadaran melestarikan kearifan lokal budaya bambu, meningkatkan rasa cinta produk dalam negeri, serta menjadi pendorong lahirnya inovasi dan gagasan yang membangun bangsa Indonesia. Sementara bagi pelaku usaha, selain peningkatan revenue, pelatihan bambu diharapkan mampu meningkatkan pertumbuhan perusahaan untuk jangka panjang. Peluang bermanuver dalam pengembangan model bisnis berbasis bambu menunjukkan bahwa bisnis bambu dengan produk yang baik bersifat tangible dan intangible sangat potensial untuk terus dikembangkan.
\end{abstract}

Kata kunci: bambu, blue ocean strategy, kanvas model bisnis, pariwisata kreatif, ekstrakurikuler

\footnotetext{
${ }^{1}$ Alamat Korespondensi:

Email:dewa.ayutenara@gmail.com
} 


\section{PENDAHULUAN}

Bambu adalah sejenis rumput dengan varietas yang sangat beragam. Komposisi kimia dan sifat mekanik dari batang bambu memungkinkan bambu digunakan secara luas. Keunggulan dari bambu diantaranya adalah kekuatan mekanik yang dapat dibandingkan dengan baja, mudah diproses, dan mudah ditanam baik diiklim tropis maupun subtropis. Keunggulan tersebut menjawab permasalahan pemenuhan hasil hutan kayu. Bahan bambu dapat digunakan sebagai materi kontruksi, desain interior, dan furnitur (Boran et al. 2013; Buckingham et al. 2014).

Kerajinan bambu merupakan salah satu identitas bangsa Indonesia yang diminati pasar luar negeri dan domestik. Terdapat bermacam-macam jenis pohon bambu di dunia, sekitar 1.250 jenis bambu di dunia, 159 jenis diantaranya terdapat di Indonesia dan 88 jenis merupakan spesies bambu endemik nusantara. Bangsa Indonesia sudah lama memanfaatkan bambu untuk bangunan rumah, perabotan, alat pertanian, kerajinan, alat musik, dan makanan (Warta Ekspor, 2011). Di dunia, Indonesia adalah negara ketiga terbesar penghasil produk bambu dan rotan. Pada tahun 2012, Cina berkontribusi sekitar 66\% pada pasar internasional, diikuti oleh Eropa 11\%, dan Indonesia 9\% (INBAR Annual Report, 2012).

Di pasar internasional, salah satu produk turunan bambu yang memiliki nilai ekonomis yang cukup tinggi adalah furnitur. Furnitur bambu yang memiliki konten lokal yang sangat tinggi, menjadikan industri furnitur dan kerajinan sebagai salah satu dari 10 prioritas produk ekspor yang bisa diandalkan untuk memacu pertumbuhan ekonomi Indonesia (Kementerian Koordinator Bidang Perekonomian, 2015).

Sebagian besar pelaku industri furnitur bambu adalah UKM (Usaha Kecil dan Menengah). CV Suratin Bamboo adalah salah satu UKM pengrajin furnitur bambu yang berlokasi di Kota Bogor, Jawa Barat, Indonesia. Selain dipasarkan di pasar domestik, produk furnitur bambu CV Suratin Bamboo juga dipasarkan ke luar negeri seperti Austria, Belanda, Italia, Jerman, dan Perancis untuk pasar Eropa, Amerika, Jepang, dan Korea Selatan untuk pasar Asia. Saat ini, pendapatan terbesar dari CV Suratin Bamboo adalah pasar ekspor. Selain karena margin keuntungan yang lebih besar daripada pasar dalam negeri, kesadaran akan isu produk ramah lingkungan, selera, dan penghargaan terhadap nilai seni kerajinan tradisional bambu lebih tinggi di mancanegara.

Sebagai sebuah usaha keluarga, pemilik CV Suratin Bamboo berencana untuk mewariskan usaha yang didirikan pada tahun 1991 kepada penerus usaha. Untuk itu perlu dilakukan pemetaan terhadap kondisi bisnis saat ini sebagai bentuk transfer knowledge dari sisi manajemen owner saat ini dan pandangannya terhadap peluang pengembangan di masa mendatang. Di kemudian hari hal ini akan sangat bermanfaat untuk mengingatkan tim penerus agar berpikir secara holistis tentang bisnis CV Suratin Bamboo dan mencegah untuk tidak tersangkut pada detail. Penelitian ini menggunakan pendekatan Business Model Canvas (Osterwalder dan Pigneur, 2014) yang dilengkapi dengan Blue Ocean Strategy (Kim dan Mauborgne, 2008) dengan harapan keterkaitan antar elemen model bisnis dapat divisualisasikan dengan baik dan penciptaan inovasi model bisnis.

Pada setiap elemen model bisnis dilakukan analisis secara intensif dengan memanfaatkan empat isu utama Blue Ocean Strategy, yaitu create, delete, increase, dan reduce. Dengan demikian diharapkan tidak hanya melakukan perbaikan, namun juga memperbesar peluang terbentuknya inovasi dalam pengembangan model bisnis, termasuk adanya pengembangan di luar kompetensi inti perusahaan. Inovasi model bisnis dalam konteks ini adalah inovasi yang menciptakan pasar baru dan menghasilkan sebuah kemampuan baru bagi pelaku usaha (Euchner dan Ganguly, 2014). Osterwalder and Pigneur's dalam "the rationale of how an organization creates, delivers, and capture value" menyatakan bahwa value adalah akar dari sebuah model bisnis. Value tidak selalu berhubungan dengan aspek finansial. Suatu set value akan menjadi target dan membawa perusahaan terhadap inovasi yang berkelanjutan (Gobble, 2014).

Isu sulitnya merekrut tenaga kerja kreatif dan rendahnya rasa cinta terhadap produk dalam negeri kerap kali muncul dalam diskusi yang melibatkan pihak CV Suratin Bamboo, Yayasan Bamboo Indonesia, Dinas Perindustrian dan Perdagangan, serta Dinas Pariwisata danEkonomi Kreatifmengenai rendahnya pertumbuhan produk turunan bambu, khususnya furnitur bambu di dalam negeri. Padahal, jika digali lebih dalam, produk turunan bambu tidak hanya bersifat tangible. Namun, 
juga intangible seperti nilai-nilai kearifan lokal khas Nusantara yang tercermin dalam teknik pembuatan produk furnitur bambu secara tradisional serta falsafah bambu yang sarat dengan nilai-nilai kehidupan (Arinasa, 2010).

Dengan demikian, tujuan penelitian ini adalah merancang prototype model bisnis masa depan yang akan digunakan untuk menemukan keseimbangan antara aspek peluang bisnis yang baru dan aspek keuntungan kompetitif (Kajanusa et al. 2014). Protoype yang dijelaskan pada tulisan ini sebenarnya adalah salah satu dari empat prototype yang dikembangkan oleh penulis. Bagi CV Suratin Bamboo, prototype model bisnis yang dikembangkan selain tentu saja berorientasi terhadap peningkatan revenue, tetapi juga bagaimana perusahaan dapat berkontribusi dalam melestarikan budaya bambu dan meningkatkan kesadaran masyarakat terhadap produk turunan bambu, khususnya furnitur bambu. Sejalan dengan tujuan tersebut, salah satu arah pengembangan prototype model bisnis yang ditawarkan peneliti bagi unit usaha berbasis bambu adalah pengembangan pada sektor pariwisata dalam bentuk creative tourism dan pendidikan dalam bentuk pilihan kegiatan ekstrakurikuler.

Creative tourism bermanfaat terhadap komunitas lokal untuk melestarikan budaya dan meningkatkan kesadaran di antara penduduk lokal (Kongrasertamon, 2007; Teparakul dan Sangsnit, 2014). Pariwisata kreatif dapat membawa perubahan yang positif dalam sebuah komunitas pada suatu negara. Meskipun, wisata kreatif seringkali dikaitkan dengan wisata budaya, sebenarnya keduanya sangatlah berbeda. Wisata budaya menitikberatkan pada melihat, merasakan, dan kontemplasi. Sementara fokus wisata kreatif adalah pengalaman otentik yang dialami oleh wisatawan. Lokasi yang spesifik dimana kegiatan kreativitas berlangsung menjadi hal terpenting dari otentifikasi tersebut. Salah satu isu strategis dalam wisata kreatif adalah penawaran keunikan budaya lokal dan kerajinan tangan (Olson dan Ivanov, 2012; Nawatnatee dan Suvachart, 2014; Singsomboon, 2014).

Kegiatan ekstrakurikuler adalah solusi yang potensial dalam menghubungkan dunia pendidikan dan industri kreatif dalam jangka panjang (Ko dan Lau, 2014). Pelajar mengikuti kegiatan ekstrakurikuler tidak jarang karena motivasi eksternal, yaitu memperbesar peluang untuk berkompetisi di pasar dunia kerja. Selain itu, kegiatan ekstrakurikuler melatih kemampuan sosialisasi dan kepemimpinan siswa, serta mengasah bakat individu yang dimiliki oleh siswa (Roulin dan Bangerter, 2013). Kegiatan extrakurikuler yang biasanya dilakukan dalam bentuk kelompok atau komunitas tertentu sangat baik bagi perkembangan anak. Berdasarkan penelitian, kegiatan ekstrakurikuler yang paling umum adalah olahraga $60 \%$, seni $25 \%$, dan selebihnya science (Ivaniushina dan Aleksandrov, 2015). Beberapa tahun terakhir terdapat pergeseran pandangan dunia terhadap hal-hal yang bersifat intangible seperti pengaruh, emosi, dan ekspresi (Crowley dan McDonald, 2015). Penelitian yang diprakarsai oleh Education Endowment Foundation (EEF) menunjukkan pelajar yang mempelajari filosofi mengalami peningkatan kemampuan matematika dan membaca. Konsepkonsep mengenai kejujuran, keadilan, persahabatan, dan pengetahuan yang dikemas dalam bentuk refleksi dalam hening, membuat dan menyatakan pertanyaan, dan membangun gagasan, mampu meningkatkan kemampuan berpikir dan mengembangkan cara baru bagi para siswa dalam berekspresi. Selain itu, para siswa menjadi lebih logis dalam berpikir dengan ideide yang saling terkoneksi (EEF, 2015).

Penjabaran dari penelitian terdahulu tersebut, mendukung ide pengembangan prototype model bisnis CV Suratin Bamboo terhadap produk turunan berbasis bambu dimana value yang ditawarkan dikemas dalam pilihan paket wisata kreatif dan kegiatan ekstrakurikuler bagi wisatawan dan pelajar.

\section{METODE PENELITIAN}

Penelitian yang dilakukan di CV Suratin Bamboo ini berlokasi di Tanah Baru, Jawa Barat, efektif dilakukan bulan November 2015 hingga Januari 2016. Pendekatan penelitian ini adalah deskriptif kualitatif berdasarkan studi kasus.

Data yang dikumpulkan dalam penelitian ini terdiri dari dua jenis data, yaitu data primer dan data sekunder. Data primer meliputi informasi, pendapat, kebijakan, dan pertimbangan yang berasal dari pihak manajemen CV Suratin Bamboo. Data primer tersebut berasal dari seluruh pekerja, jajaran manajemen CV Suratin Bamboo, dan pandangan para pakar. Informasi tersebut terkait dengan permasalahan yang dihadapi, kegiatan yang dilakukan, kondisi sumberdaya yang dimiliki, serta peluang dan ancaman yang dihadapi oleh CV 
Suratin Bamboo. Adapun Daftar responden dalam penelitian ini dapat dilihat pada Tabel 1. Data sekunder diperoleh melalui studi literatur menyangkut isu strategis industri, serta kondisi usaha dan perusahaan secara umum yang berasal dari dokumen tertulis atau laporan internal perusahaan.

Teknik pengumpulan data dan informasi dilakukan melalui: 1) observasi dengan melakukan pengamatan langsung di lingkungan internal CV Suratin Bamboo; 2) wawancara terstruktur baik dengan responden internal dan eksternal dengan menggunakan alat bantu kuisioner; 3) studi pustaka, yaitu dengan mengkaji data perusahaan dan penelusuran studi literatur; 4) Studi dokumentasi berfungsi untuk melengkapi data dan informasi yang telah diperoleh sebelumnya; 5) Workshop bersama pekerja selain tim manajemen dengan tujuan memperkaya pandangan mengenai model bisnis saat ini dan masa depan; 6) Focus Group
Discussion (FGD) bersama tim manajemen dipimpin oleh direktur utama dengan tujuan mengevaluasi dan merancang model bisnis masa depan.

Penelitian ini terdiri dari dua tahap. Tahapan pertama adalah mengambil potret model bisnis saat ini. Pada kerangka konseptual (Gambar 1) terlihat kesembilan elemen model bisnis yang dilakukan dalam analisis internal dituangkan dalam satu lembar kanvas sebagai potret model bisnis saat ini untuk mempermudah visualisasi model bisnis. Tahapan berikutnya adalah menafsirkan ulang strategi melalui dengan analisis Business Model Canvas (BMC). Untuk itu, dilakukan pendalaman terhadap empat bidang strategis, yaitu lingkungan model bisnis melalui analisis ruang desain model bisnis, evaluasi model bisnis dengan analisis SWOT, perspektif model bisnis dengan Blue Ocean Strategy (BOS), dan bagaimana mengelola model bisnis dalam perusahaan (Osterwalder dan Pigneur, 2014).

Tabel 1. Daftar responden internal dan eksternal

\begin{tabular}{lcc}
\hline \multicolumn{1}{c}{ Daftar responden } & Jumlah & Keterangan \\
\hline Direktur CV Suratin Bamboo & 1 & Responden internal 15 orang \\
Project manager perdagangan umum dan furniture & 1 & \\
Manajer administrasi umum dan keuangan & 1 & \\
Tenaga kreatif CV Suratin Bamboo & 12 & \\
Dinas Perindustrian dan Perdagangan Bidang IKM & 1 & Responden eksternal 3 orang \\
Dinas Pariwisata dan Ekonomi Kreatif & 1 & \\
Yayasan Bambu Indonesia & 1 & \\
\hline \multicolumn{1}{c}{ Total } & 18 & \\
\hline
\end{tabular}

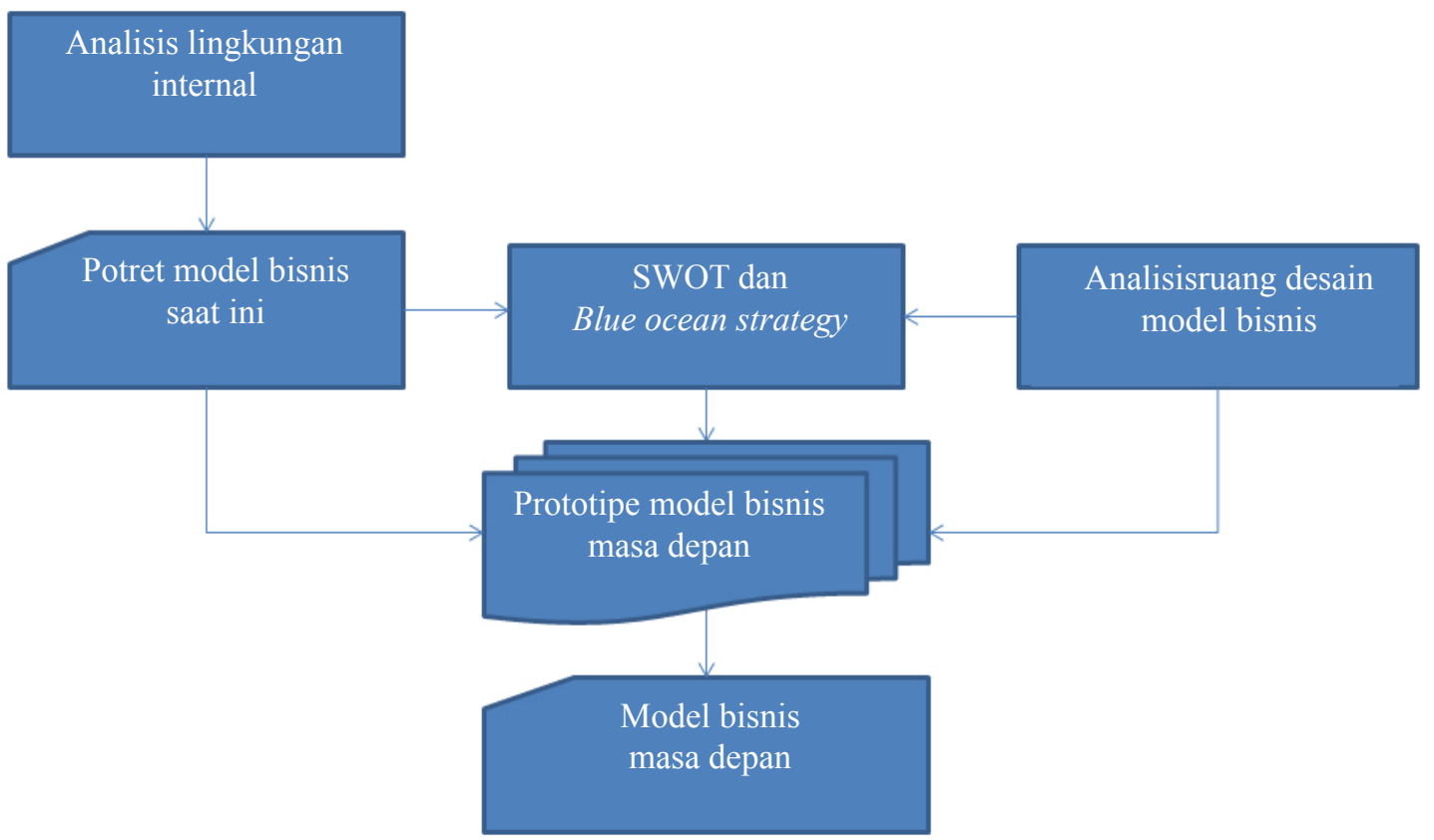

Gambar 1. Kerangka pemikiran penelitian 


\section{HASIL}

\section{Potret Model Bisnis Saat Ini}

Pertama-tama peneliti melakukan observasi dan wawancara mendalam terhadap lingkungan internal CV Suratin Bamboo yang terdiri dari sembilan elemen model bisnis CV Suratin Bamboo yang terdiri dari: Customer Segments, Value Propositions, Channels, Customer Relationships, Revenue Streams, Key Activities, Key Resources, Key Partnerships, Cost Structure. Kemudian dilakukan pemetaan terhadap masing-masing blok elemen model bisnis. Hasil pemetaan dari setiap elemen model bisnis dituangkan dalam satu lembar kanvas sebagai potret model bisnis saat ini pada Gambar 2.

\section{Perspektif Model Bisnis dengan Blue Ocean Strategy}

Penelitian ini menggunakan metode FGD dan Workshop. Metode FGD dilakukan bersama owner dan tim manajemen memiliki fungsi antara lain untuk menentukan bentuk kanvas model bisnis yang sesuai dengan kondisi lingkungan model bisnis CV Suratin Bamboo saat ini, melakukan evaluasi model bisnis dengan analisis SWOT setiap elemen BMC, dan merancang prototype model bisnis masa depan dengan BOS. Workshop dilakukan dengan tenaga kreatif dan staf untuk memperkaya pandangan mengenai bisnis yang telah dijalankan beserta gambaran peluang di masa mendatang. Hasil studi literatur, wawancara dengan pakar, FGD, dan workshop tersebut dianalisis secara kualitatif sehingga menghasilkan rekomendasi prototype model bisnis masa depan untuk CV Suratin Bamboo.

\begin{tabular}{|c|c|c|c|c|}
\hline $\begin{array}{l}\underline{K E Y} \\
\underline{P A R T N E R S H I P S}\end{array}$ & $\underline{\text { KEY ACTIVITIES }}$ & 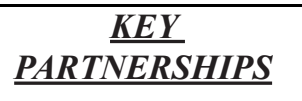 & $\begin{array}{c}\frac{\text { Customer }}{\text { RELATIONSHIP }} \\
\underline{\text { LATION }}\end{array}$ & $\begin{array}{l}\text { Customer } \\
\underline{\text { Segments }}\end{array}$ \\
\hline $\begin{array}{c}\text { Pemasok bahan } \\
\text { baku utama }\end{array}$ & Aktivitas produksi & $\begin{array}{l}\text { Produk ramah } \\
\text { lingkungan }\end{array}$ & Layanan personal & $\begin{array}{l}\text { Pembeli furnitur } \\
\text { bambu }\end{array}$ \\
\hline $\begin{array}{l}\text { Pemasok bahan } \\
\text { baku penunjang }\end{array}$ & $\begin{array}{c}\text { Aktivitas } \\
\text { pemasaran }\end{array}$ & $\begin{array}{c}\text { Produk bambu } \\
\text { berkualitas }\end{array}$ & & $\begin{array}{c}\text { Pembeli handicraft } \\
\text { bambu }\end{array}$ \\
\hline Pemerintah & $\begin{array}{c}\text { Aktivitas jasa } \\
\text { pelatihan }\end{array}$ & Co-Creation & & $\begin{array}{l}\text { Peserta pelatihan } \\
\text { bambu }\end{array}$ \\
\hline Pelaku usaha sejenis & KEYRESOURCES & \multirow{2}{*}{$\begin{array}{l}\text { Jasa pelatihan bam- } \\
\text { bu yang bersahabat }\end{array}$} & CHANNELS & \\
\hline Pengrajin bambu & Tenaga kreatif & & $\begin{array}{l}\text { Website dan media } \\
\text { sosial }\end{array}$ & \\
\hline & Sumber daya fisik & & Showroom & \\
\hline & $\begin{array}{c}\text { Sumber daya } \\
\text { intelektual }\end{array}$ & & Pameran & \\
\hline \multicolumn{2}{|l|}{ COST STRUCTURES } & \multicolumn{2}{|c|}{$\underline{R E V E N U E S T R E A M S}$} & \\
\hline \multicolumn{2}{|c|}{ Biaya operasional produksi } & \multicolumn{2}{|c|}{ Penjualan furnitur } & \\
\hline \multicolumn{2}{|l|}{ Gaji pegawai } & \multicolumn{2}{|c|}{ Penjualan handicraft } & \\
\hline \multicolumn{2}{|l|}{ Biaya pemasaran } & \multicolumn{2}{|c|}{ Pendapatan jasa pelatihan } & \\
\hline
\end{tabular}

Gambar 2 Potret Model Bisnis CV Suratin Bamboo Januari 2016 
Ide perencanaan model bisnis berbasis bambu ini adalah pengembangan pelatihan bambu yang mulai dijalankan sejak tahun 2013. Namun, tampaknya belum dianggap sebagai ladang usaha. Selama ini pelatihan inovasi dan kewirausahaan yang diadakan oleh tim CV Suratin Bamboo dilakukan berdasarkan inisiatif permintaan institusi terkait. Di masa mendatang, kegiatan pelatihan dapat membidik dua sektor, yaitu sektor pariwisata sebagai bagian dari creative tourism dan sektor pendidikan sebagai bagian dari pilihan kegiatan ekstrakurikuler. Pengembangan model bisnis ini tidak semata-mata berorientasi pada profit, namun juga kepada bagaimana pelaku usaha kerajinan berbasis bambu dapat berkontribusi secara langsung dalam melestarikan budaya bambu sebagai warisan leluhur, ikut serta dalam pembentukan budi pekerti dan kecintaan terhadap alam melalui falsafah nilai-nilai kearifan lokal yang dimiliki oleh bambu, mencetak tenaga kreatif sejak dini, dan membangkitkan semangat inovasi sejak dini. Dengan demikian, kesadaran dan penghargaan pasar domestik terhadap produk turunan bambu dalam hal ini furniture dan handicraft akan meningkat sejalan dengan respon pasar domestik terhadap produk turunan bambu yang lebih baik di masa mendatang.
Osterwalder dan Pigneur menggunakan analogi keseimbangan otak kiri (logika) dan kanan (kreativitas) dalam pendekatan kanvas model bisnis seperti yang diilustrasikan oleh Gambar 3. Agar model bisnis dapat berjalan, perubahan pada setiap elemen model bisnis harus dilihat sebagai satu kesatuan model bisnis. Dengan demikian, perubahan pada satu blok elemen berdampak pada blok elemen model bisnis yang lain.

Alur perancangan prototype model bisnis dengan BOS yang mengangkat empat pertanyaan utama, yaitu apa yang bisa diciptakan (create), dihilangkan (eliminate), ditingkatkan (rise), dan dikurangi (reduce) yang mengacu pada kondisi saat ini dan kondisi di masa mendatang ditunjukkan Gambar 4. Penomoran yang didukung oleh tanda panah pada gambar menunjukkan urutan ide, bagaimana perubahan ataupun penambahan pada satu blok bangunan memengaruhi blok bangunan yang lain. Peneliti menggunakan perbedaan warna pada panah untuk memperjelas pemaparan.

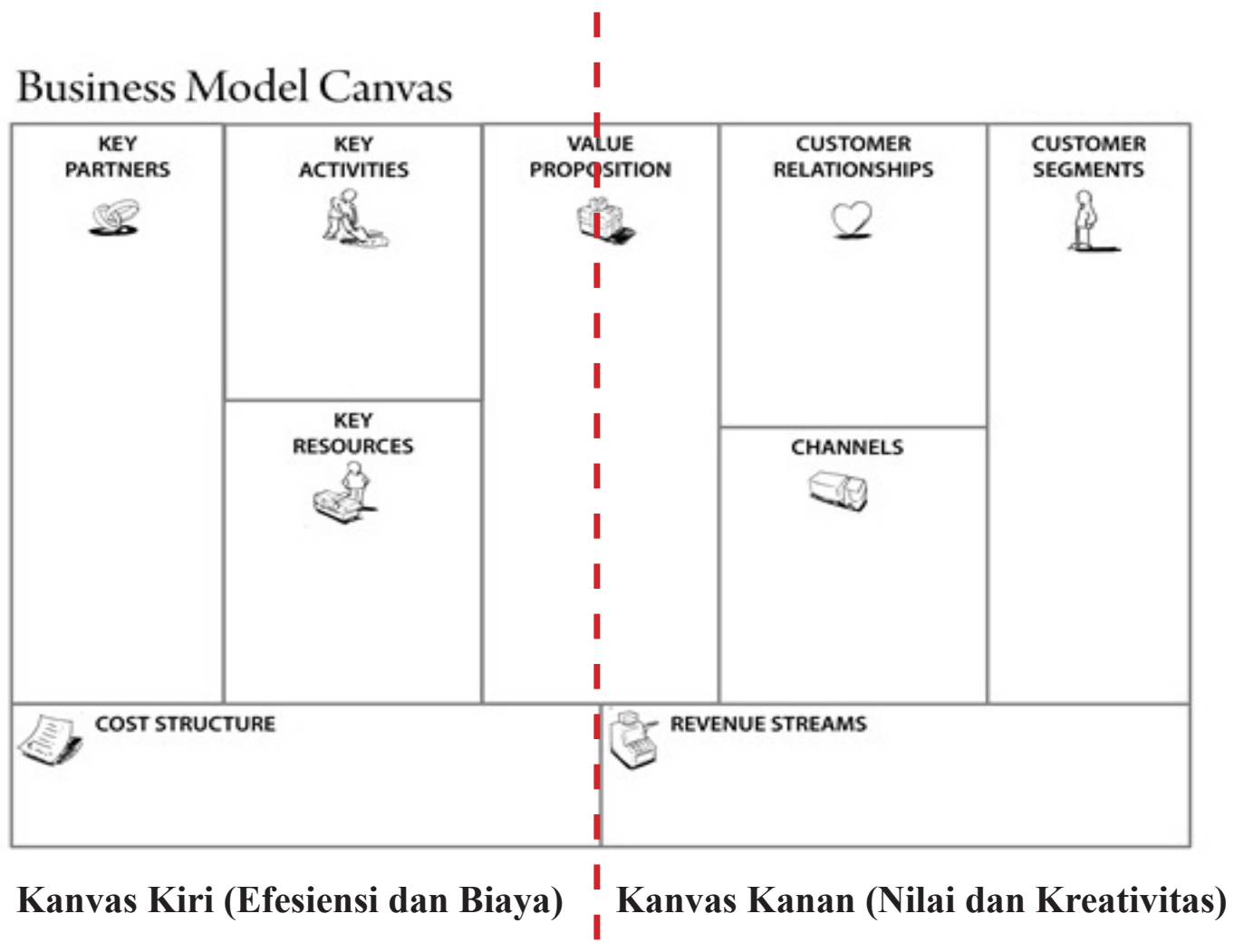

Gambar 3. Ilustrasi kanvas sisi kanan dan sisi kiri 


\begin{tabular}{|c|c|c|c|c|}
\hline TATANAN BANGUNAN & Create & ELIMINATE & RISE & $R E D U C E$ \\
\hline $\begin{array}{l}\text { Siapa perusahaan dan apa } \\
\text { yang perusahaan miliki? } \\
(\text { Key Resources) }\end{array}$ & \begin{tabular}{l}
\multicolumn{1}{c}{6} \\
- Tenaga pengajar terampil \\
- Modul \\
- Portofolio \\
- Balai pelatihan
\end{tabular} & & $\begin{array}{l}\longrightarrow \text { - } 6 \text { Showroom yang } \\
\text { ramah anak } \\
\text { - Bengkel produksi } \\
\text { yang rapi }\end{array}$ & \\
\hline $\begin{array}{l}\text { Apa yang perusahaan } \\
\text { lakukan? (Key Activities) }\end{array}$ & \begin{tabular}{l}
\multicolumn{1}{c}{7} \\
- Perekrutan tenaga pengajar \\
- Penyusunan materi \\
pelatihan \\
- Promosi paket kegiatan \\
pelatihan \\
- Aktivitas pengajaran
\end{tabular} & & & \\
\hline $\begin{array}{l}\text { Siapa yang perusahaan } \\
\text { bantu? (Customer } \\
\text { Segments) }\end{array}$ & $\begin{array}{l}\quad 1 \\
\text { - Pelajar } \\
\text { - Enterpreneur }\end{array}$ & & $\begin{array}{l}\rightarrow \\
\text { Wisatawan }\end{array}$ & \\
\hline $\begin{array}{l}\text { Bagaimana cara } \\
\text { perusahaan membantu? } \\
\text { (Value Propositions) }\end{array}$ & $\begin{array}{l}\text { - Falsafah bambu } \\
\text { - Budidaya dan pengelolaan } \\
\text { bambu } \\
\text { - Desain handicraft bambu } \\
\text { - Pembuatan handicraft } \\
\text { bambu }\end{array}$ & & $\begin{array}{l}\rightarrow \text { - } \\
\text { - Pengeringan } \\
\text { dan pengawetan } \\
\text { bambu } \\
\text { - Desain furniture } \\
\text { bambu } \\
\text { - Pembuatan } \\
\text { furniture bambu }\end{array}$ & \\
\hline $\begin{array}{l}\text { Bagaimana perusahaan } \\
\text { dikenal? (Channels) }\end{array}$ & \begin{tabular}{l}
\multicolumn{1}{c}{4} \\
- Katalog eksklusif \\
- Presentasi online di youtube
\end{tabular} & & $\begin{array}{l}-\quad 4 \\
\text { - Kantor pemasaran } \\
\text { - Website } \\
\text { representatif }\end{array}$ & \\
\hline $\begin{array}{l}\text { Bagaimana perusahaan } \\
\text { berinteraksi? (Customer } \\
\text { Relationships) }\end{array}$ & - Testimoni & & & \\
\hline $\begin{array}{l}\text { Siapa yang membantu } \\
\text { perusahaan? (Key } \\
\text { Partnerships) }\end{array}$ & $\begin{array}{l}\quad 3 \\
\text { - Sekolah } \\
\text { - Universitas } \\
\text { - Tour guide }\end{array}$ & & $\begin{array}{l}\text { - Pengrajin bambu } \\
\text { - Pemerintah }\end{array}$ & \\
\hline $\begin{array}{l}\text { Apa yang perusahaan } \\
\text { dapatkan? (Revenue } \\
\text { Streams) }\end{array}$ & $\begin{array}{c}8 \\
\text { - Pendapatan jasa pelatihan }\end{array}$ & & & \\
\hline $\begin{array}{l}\text { Apa yang perusahaan } \\
\text { berikan? (Cost Structure) }\end{array}$ & \begin{tabular}{l}
\multicolumn{1}{c}{9} \\
- Biaya tambahan bagi \\
tenaga pengajar \\
- Biaya pembuatan materi \\
promosi \\
- Biaya persiapan materi \\
pengajaran \\
- Biaya investasi \\
infrastruktur
\end{tabular} & & & \\
\hline
\end{tabular}

Gambar 4. Blue Ocean Strategy dalam prototype model bisnis CV Suratin Bamboo 
Berikut keterangan untuk masing-masing tahapan perubahan blok bangunan:

1. Jasa pelatihan ini menargetkan pelanggan institusi tertentu seperti sekolah bagi pelajar TK sampai universitas, pengusaha, dan wisatawan.

2. Value yang ditawarkan oleh CV Suratin Bamboo adalah pelatihan bambu yang dikemas dalam paket wisata dan kegiatan ekstrakurikuler. Materi yang diajarkan adalah falsafah bambu, budidaya dan pengelolaan bambu, pengeringan dan pengawetan bambu, desain furnitur dan handicraft bambu, dan pembuatan furnitur dan handicraft bambu.

3. Untuk dapat merealisasikan model bisnis tersebut, CV Suratin Bamboo dapat bekerja sama dengan sekolah, universitas, pengrajin bambu, tour guide, dan tentu saja pemerintah setempat.

4. Program-program pelatihan yang ditawarkan oleh CV Suratin Bamboo dipromosikan melalui website yang representatif, presentasi online di youtube, dan katalog eksklusif. Selain itu, CV Suratin Baru juga perlu memiliki kantor pemasaran.

5. CV Suratin Bamboo memanfaatkan testimoni sebagai sarana untuk mendapatkan voice of Customer sekaligus mempromosikan pelayanan yang diberikan dalam kegiatan pelatihan.

6. Untuk itu, perekrutan tenaga pengajar, penyusunan materi pengajaran, promosi paket kegiatan, dan aktivitas pengajaran akan menjadi aktivitas utama di awal penyelenggaraan pelatihan.

7. Dengan demikian akan ada pengeluaran $\mathrm{CV}$ Suratin Bamboo untuk biaya tenaga pengajar, persiapan materi pembelajaran, termasuk investasi infrastruktur seperti balai pelatihan dan penataan showroom yang ramah anak.

8. Sumber pendapatan dari pelatihan ini adalah pendapatan dari jasa pelatihan yang diselenggarakan bagi pelajar, enterpreneur, dan wisatawan.

\section{Prototype Model Bisnis Masa Depan}

Seperti halnya pada pemetaan potret model bisnis saat ini, BOS yang diimplementasikan dalam pengembangan model diilustrasikan oleh Gambar 4 juga dipetakan dalam satu lembar kanvas. Hasil pemetaan tersebut divisualisasikan oleh Gambar 5 sebagai salah satu prototype model bisnis masa depan CV Suratin Bamboo. Peneliti memanfaatkan pewarnaan pada kotak-kotak anggota blok elemen model bisnis yaitu jingga, hijau, dan tanpa warna. Warna jingga bagi anggota blok elemen yang ditambahkan atau diciptakan (create), hijau bagi anggota blok elemen yang ditingkatkan atau dioptimalkan aktivitasnya jika dibandingkan dengan yang model bisnis yang terdahulu, sementara kotak tanpa warna adalah anggota blok elemen model bisnis CV Suratin Bamboo saat ini yang tetap dipertahankan tanpa rencana perubahan apapun di masa mendatang.

Berikut adalah penjelasan dari masing-masing elemen blok bangunan pada prototype model bisnis masa depan CV Suratin Bamboo:

\section{Customer Segments}

Motivasi dipisahkannya segmen pelanggan jasa pelatihan adalah kebutuhan dari calon peserta pelatihan bambu. Salah satu sekolah alam di Bogor, mengajak para siswanya mengunjungi tempat produksi CV Suratin Bamboo, untuk memperkenalkan para siswa manfaat dari tanaman yang ada di sekitarnya, memperkenalkan jenis pekerjaan di bidang industri kreatif, dan menumbuhkan kecintaan pada alam. Salah satu universitas di Lampung mengundang CV Suratin Bamboo untuk melakukan pendampingan dalam kegiatan inovasi. Lain lagi dengan universitas di Sulawesi Utara, yang mengundang CV Suratin Bamboo untuk memberikan motivasi untuk memulai wirausaha sejak dini kepada para siswa. Sebagai referensi, di Yayasan Bamboo Indonesia, para peserta pelatihan selain pemerhati budaya dan kearifan lokal, juga pengusaha yang ingin mencoba peruntungan di bisnis berbasis bambu memilih melakukan penjajakan terlebih dahulu dengan mengikuti pelatihan. Dengan demikian, untuk peluang pengembangan model bisnis CV Suratin Bamboo dalam jasa pelatihan segmen pelanggan terdiri dari:

a. Institusi pendidikan taman kanak-kanak sampai universitas

b. Pelaku usaha produk yang berbasis bambu dan calon pengusaha yang mencari ide usaha ataupun menjajaki seluk beluk usaha furnitur bambu pada khususnya dan kerajinan bambu pada umumnya.

c. Wisatawan pencinta budaya lokal khususnya budaya bambu

\section{Value Propositions}

Penyajian pelatihan bambu disesuaikan berdasarkan usia dan jenjang pendidikan. Bagi calon pengusaha kegiatan ini bermanfaat dalam menambah wawasan teknis membuat bambu maupun mengelola usaha bambu. Bagi para akademisi dan orang tua, kegiatan ekstrakurikuler bambu bermanfaat dalam menstimulus 
kreativitas dan mengarahkan minat dan bakat anak sejak dini. Untuk mendukung kegiatan ini, pelatihan bambu dapat dilakukan dengan outbond sehingga seluk beluk usaha furnitur bambu dapat dipaparkan dengan lebih nyata. Berikut adalah contoh dari materi pembahasan yang akan dikemas dalam beberapa paketpaket pelatihan seperti berikut:

a. Falsafah bambu

Budaya bambu adalah budaya khas Indonesia. Banyak nilai-nilai kearifan lokal yang memiliki nilai edukasi yang sangat baik bagi para pelajar. Penyajiannya dapat dilakukan bersamaan dengan kegiatan outbond sebagai bagian dari kegiatan pembentukan karakter. Berikut ini adalah contoh nilai-nilai kehidupan bambu khas Cimande (Nanggamihardja, 2012) yang baik bagi pendidikan budi pekerti:
- "Wetek awi lenjeuran henteu cagakan" (sifat bambu lurus batangnya, tidak bercabang). Artinya, memiliki tujuan hidup yang pasti dan jelas.

- "Watek awi leunjeran awi leuleus layeus" (sifat bambu memiliki daya kelenturan). Artinya, harmoni dan fleksibel dalam pergaulan.

- "Watek awi ngakut cai nyuburkeun taneuh, mupuk maneh ku dauna" (sifat bambu menyimpan air dan menyuburkan tanah, memberi pupuk oleh daunnya sendiri). Artinya, sifat bambu adalah lambang sumber kehidupan, kemakmuran, kesejahteraan, dan kemandirian.

b. Budidaya dan pengelolaan bambu

c. Pengeringan dan pengawetan bambu

d. Desain furnitur dan handicraft bambu

e. Pembuatan furnitur dan handicraft bambu

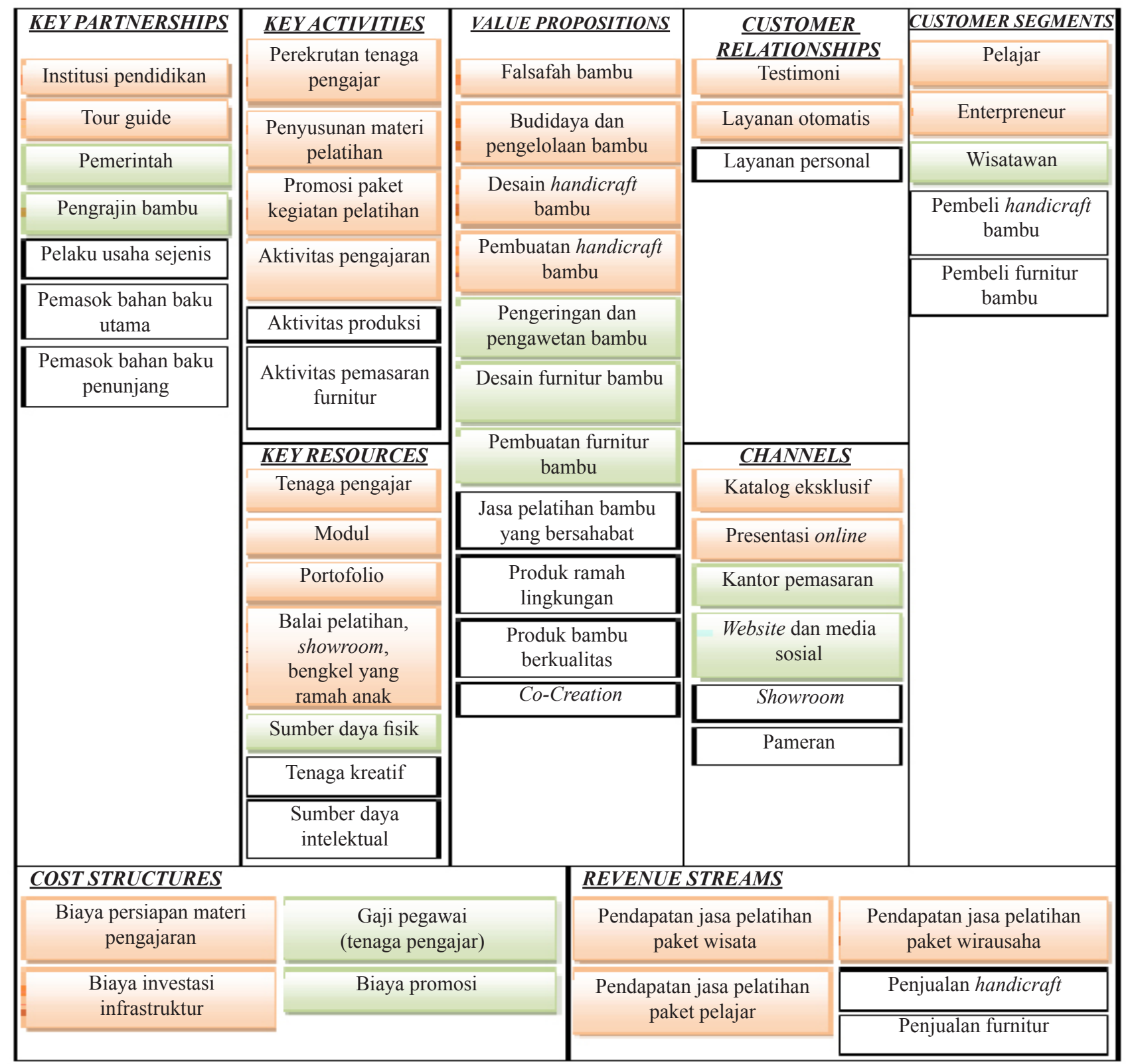

Gambar 5. Prototype model bisnis masa depan CV Suratin Bamboo 


\section{Channels}

Jika model bisnis ini diterapkan, maka perlu dilakukan update informasi pada konten website yang didukung oleh penampilan yang representatif. Untuk itu, content website perlu dilengkapi dengan Search Engine Optimizations (SEO). Selain itu perusahaan perlu menampilkan presentasi online yang dapat dimunculkan pada media sosial. Katalog eksklusif baik untuk memperkuat citra profesional CV Suratin Bamboo. Seiring dengan berkembangnya usaha, CV Suratin Bamboo perlu memiliki bengkel produksi, showroom, dan balai pelatihan yang ramah bagi anak. Agresifitas aktivitas pameran perlu ditingkatkan, tidak hanya untuk mempromosikan produk furnitur bambu, namun juga kegiatan pelatihan bambu.

\section{Customer relationships}

Layanan pelanggan dilakukan secara personal dengan testimoni peserta kegiatan sebagai nilai tambah. Selain itu, layanan otomatis juga dapat dilakukan melalui website terkait dengan waktu pemesanan paket kegiatan pelatihan.

\section{Key activities}

Berikut aktivitas kunci jika prototype model bisnis ini diimplementasikan di masa mendatang:

a. Merekrut tenaga pengajar

b. Penyusunan materi pengajaran

c. Promosi paket kegiatan

Rincian kegiatan dapat dipresentasikan dalam website dan presentasi online, serta katalog. Sebagai tahap awal penawaran, CV Suratin Bamboo dapat menerapkan program gratis, bekerja sama dengan institusi pemerintah sebagai pelanggan korporat. Paket kegiatan ekstrakurikuler dengan beberapa kali pertemuan dapat ditawarkan sebagai tawaran awal untuk dapat menyajikan materi pelatihan yang disajikan dalam jangka waktu yang lebih lama. Materi falsafah bambu misalnya, baik untuk dijadikan bahan materi pendidikan budi pekerti bagi siswa taman kanak-kanan hingga sekolah. Sementara bagi siswa menengah pertama hingga siswa menengah ke atas, materi perancangan dan pembuatan furnitur bambu dapat memberikan gambaran mata pencaharian alternatif selepas lulus sekolah. Bagi mahasiswa, materi pengelolaan usaha bambu dapat menjadi pilihan bagi mereka yang tertarik berwirausaha.

\section{Key resources}

Sumber daya utama dari prototype model bisnis ini terdiri atas tenaga pengajar yang terampil dan komunikatif, modul untuk menyajikan materi pelatihan dengan sistematis, dan portofolio produk untuk meningkatkan kepercayaan dari pelanggan. Selain itu sumber daya fisik dalam bentuk bangunan perlu dibenahi. Atmosfer showroom memiliki peranan yang penting dalam menarik pelanggan secara tidak langsung. Atmosfer yang mengacu pada desain lingkungan yang terdiri dari komunikasi visual, pencahayaan, penggunaan warna, musik, dan aroma menstimulus persepsi pelanggan dan membangkitkan sisi emosional yang berpengaruh terhadap perilaku pembelian (Pramatatya et al. 2015). Untuk itu sumber daya fisik dalam bentuk bengkel, showroom, dan balai pelatihan perlu dibenahi.

\section{Key partnerships}

Sebagai pelaku usaha di industri kreatif yang merupakan bagian dari suatu sistem, untuk menjalankan prototype model bisnis ini CV Suratin Bamboo perlu mengoptimalkan kerja sama dengan pihak-pihak di bawah ini:

a. Instansi pemerintah

Contoh instansi pemerintah yang berhubungan dengan pengembangan usaha adalah Dinas Industri dan Perdagangan, Dinas Pariwisata dan Ekonomi Kreatif, dan Dinas Pendidikan dan Kebudayaan.

b. Sekolah dan Universitas

Karena salah satu target pelanggan adalah kalangan pelajar maka sekolah dan universitas adalah mitra utama dalam model bisnis pelatihan bambu.

c. Pengrajin bambu

Dengan dijalankannya model bisnis ini oleh CV Suratin Bamboo maka para tenaga kreatif memiliki pilihan sumber pendapatan dengan membagikan ilmunya, yang merupakan produk intangible, kepada pihak lain sebagai tenaga pengajar.

d. Tour guide

Tour guide sangat berperan dalam memberikan informasi paket wisata bagi wisatawan. Di masa mendatang pelatihan bambu dapat menjadi alternatif pariwisata kreatif di Kota Bogor.

\section{Cost structure}

Konsekuensi dari menjalankan prototype model bisnis ini adalah penambahan pada beberapa pengeluaran 
seperti biaya investasi infrastruktur seperti penataan showroom yang nyaman dan ramah anak dan balai pelatihan, biaya persiapan materi pengajaran baik yang berupa literatur maupun bahan baku dan material pembuatan bambu, biaya gaji pengajar, dan tentu saja biaya promosi.

\section{Revenue streams}

Prototype model bisnis ini menawarkan tambahan pendapatan dari jasa pelatihan bambu yang terdiri dari paket pelajar, wisata, dan wirausaha.

\section{Implikasi Manajerial}

Setelah prototype dikembangkan, tahapan selanjutnya adalah perusahaan menentukan prototype yang dianggap terbaik. Dalam hal ini, pada setiap prototype peneliti memberikan estimasi waktu dan biaya. Tabel
2 adalah estimasi biaya yang harus disiapkan oleh perusahaan untuk pengembangan perusahaan pada tahun pertama yaitu Rp194.000.000. Sementara itu, pada Tabel 3 dapat dilihat estimasi waktu persiapan yang dibutuhkan sampai prototype model bisnis ini siap dijalankan. Waktu yang dibutuhkan untuk mempersiapkan prototype model bisnis adalah dua tahun sampai benar-benar matang untuk dijalankan. Hal ini berkaitan dengan usaha jasa pelatihan bambu yang secara kompetensi inti berbeda dari model bisnis yang dijalankan saat ini.

Selain itu, kelebihan dan kelemahan dari setiap prototype dipertimbangkan, yang bersesuaian dengan peluang dan kapasitas perusahaan. Dalam hal ini, kelebihan dan kekurangan dari prototype model bisnis yang dipaparkan dalam tulisan ini dapat dilihat pada Tabel 4.

Tabel 2. Estimasi biaya persiapan running prototype model bisnis 1

\begin{tabular}{lrr}
\hline \multicolumn{1}{c}{ Keterangan } & Term I (Rp) & Term II (Rp) \\
\hline Menata infrastruktur yang ramah anak seperti showroom dan balai pelatihan & 50.000 .000 & 500.000 \\
Rekrutmen tenaga pengajar & 5.000 .000 & 5.000 .000 \\
Materi promosi dan branding "Suratin Bamboo" & 5.000 .000 & 5.000 .000 \\
Aktivitas pemasaran & 5.000 .000 & 10.000 .000 \\
Sarana belajar (modul, portofolio produk, dan alat pendukung pelatihan) & 54.000 .000 & 54.000 .000 \\
Gaji tambahan pegawai tiga orang tenaga pengajar & 194.000 .000 \\
\hline \multicolumn{1}{c}{ Total term 1+ term II } &
\end{tabular}

Tabel 3. Estimasi waktu persiapan running prototype model bisnis 1

\begin{tabular}{|c|c|c|c|c|c|c|c|c|}
\hline \multirow{2}{*}{ Program Kerja } & \multicolumn{8}{|c|}{ Quartal ke - ... } \\
\hline & 1 & 2 & 3 & 4 & 5 & 6 & 7 & 8 \\
\hline \multicolumn{9}{|l|}{ Menata infrastruktur yang ramah anak } \\
\hline \multicolumn{9}{|l|}{ Branding "Suratin Bamboo" } \\
\hline \multicolumn{9}{|l|}{ Menyusun struktur penggajian pegawai } \\
\hline \multicolumn{9}{|l|}{ Rekrutmen tenaga pengajar } \\
\hline \multicolumn{9}{|l|}{ Edukasi tenaga pengajar } \\
\hline \multicolumn{9}{|l|}{ Menyusun materi paket pelatihan bambu } \\
\hline Promosi program pelatihan & & & & & & & & \\
\hline
\end{tabular}

Tabel 4. Perbandingan kelebihan dan kelemahan dari prototype model bisnis

Kelebihan Kelemahan

Membuka kesempatan yang luas pada CV Suratin Bamboo Waktu persiapan yang dibutuhkan lama (dua tahun) untuk berkontribusi lebih dalam melestarikan budaya

Nusantara

Potensi pengembangan usaha yang luas di sektor pariwisata Pengembangan usaha di luar kompetensi inti CV Suratin dan pendidikan

Bamboo

Potensi perolehan pendapatan tinggi

Estimasi modal awal pengembangan cukup tinggi 


\section{KESIMPULAN DAN SARAN}

\section{Kesimpulan}

Hasil penelitian menunjukkan CV Suratin Bamboo adalah pelaku usaha kerajinan bambu (furnitur bambu) dengan pengelolaan usaha secara konvensional mampu menembus pasar internasional. Usaha ini memiliki potensi untuk dikembangkan, hal ini terlihat dari peluang bermanuver dengan melakukan perbaikan dan inovasi model bisnis sebagai respon terhadap lingkungan industri kreatif yang sedang bertumbuh. Prototype model bisnis yang dihasilkan adalah salah satu dari empat prototype model bisnis yang dihasilkan oleh peneliti. Prototype model bisnis yang bergerak dalam sektor pariwisata kreatif dan pendidikan selain berorientasi pada peningkatan revenue. Dengan demikian, mampu memberi ruang bagi CV Suratin Bamboo untuk meningkatkan kesadaran masyarakat mengenai budaya bambu dan produk turunan bambu.

\section{Saran}

Sebelum prototype model bisnis ini dijalankan, perlu dilakukan analisis secara finansial seperti budgetting dan penjajakan terhadap masing-masing segmen pelanggan dengan pendekatan kanvas model bisnis. Dengan demikian, resiko kerugian di masa mendatang dapat diminimalisir dan dimitigasi sejak awal (Dudin et al. 2015). Secara berkala, penerus usaha bersama tim manajemen disarankan melakukan perancangan model bisnis dengan pendekatan kanvas model bisnis untuk melakukan evaluasi dan melihat adanya peluang pengembangan baru. Prototype model bisnis yang ada dan belum terpakai dapat disimpan sebagai bank prototype yang dapat diwariskan kepada penerus usaha selanjutnya di kemudian hari sebagai bank ide. Untuk mengoptimalkan pertumbuhan usaha, kerja sama yang baik perlu dijalin antara akademisi (cendekiawan), pemerintah, dan pelaku usaha sejenis dalam industri kreatif (Departemen Perdagangan RI, 2008).

\section{DAFTAR PUSTAKA}

Arinasa IBK, 2010. Bamboo diversity and utilization in Balinese rituals at Angsri Village-Bali, Indonesia. Bamboo Science and Culture. The Journal of the American Bamboo Society 23(1):29-37.
Buckingham KC, Wu L, Lou Y. 2014. Can't see the (Bamboo) forest for the trees: examining Bamboo's fit within international forestry institutions. Ambio Royal Swedish Academy of Sciences 43:770-778.

Boran S, Cavdar AD, Barbu MC. 2013. Evaluation of bamboo as furniture material and its furniture designs. Pro Ligno 9(4):811-819.

Crowley V, McDonald. 2015. Affective strategies in the academy: creative methodologies, civic responses, and the market. Social alternatives 34(2):6-11.

Departemen Perdagangan Republik Indonesia. 2008. Pengembangan Ekonomi Kreatif Indonesia 2025: Rencana Pengembangan Ekonomi Kreatif Indonesia 2009-2015. Jakarta: Departemen Perdagangan Republik Indonesia.

Dudin MN, Kutsuri GN, Fedorova IJ, Dzusova SS, Namitulina AZ. 2015. The innovative business model canvas in the system of effective budgeting. Asian Social Science 11(7):290-297. doi:10.5539/ass.v11n7p290.

[EEF] Education Endowment Foundation. 2015. Philosophy for Children: Evaluation Report and Executive Summary. London: EEF.

Euchner J, Ganguly A. 2014. Business Model Innovation in Practice. A Systematic Approach to Business Model Innovation can Help Capture Value and Reduce Risk. Research-Technology Management. November-December:33-39. doi:10.5437/08956308X5706013.

Gobble MA. 2014. Business model innovation. research-technology management. ResearchTechnology Management 57: 58-60. doi:10.5437/08956308X5706005.

[INBAR] International Network for Bamboo and Rattan. 2013. Annual Report 2012.

Ivaniushina VA, Aleksandrov DA. 2015. Socialization through informal education: the extracurricular acivities of russian school children. Russian Education and Society 57(4):189-213.

Kim C, Mauborgne R. 2008. Blue Ocean Strategy. Jakarta:PT Serambi Ilmu Semesta.

Kajanusa M, Iirea A, Eskelinena T, Heinonenb M, Hansen E. 2014. Business model design: new tools for business systems innovation. Scandinavian Journal of Forest Research 29(6):603-614.

Ko J, Lau D. 2014. From creativity to creative industries: a curly road that education can contribute. Journal of Youth Studies 17(2):35-49. 
Kongprasertamorn K. 2007. Local wisdom environmental protection and community development: the clam farmers in Tambon Bangkhunsai, Phetchaburi Province, Thailand. Manusya: Journal of Humanities 10(1):1-10.

Nanggamihardja J. 2012. Serumpun Bambu Sejuta Karya. Bogor: Yayasan Senam Hijaiyah Indonesia.

Nawatnatee T, Suvachart N. 2014. Local wisdom to creative cultural tourism activity. Journal of tourism and Hospitality Management 2(2):7784.

Olson RO, Ivanov S. 2010. Creative tourism business model and Its application in Bulgaria. Di dalam: Cultural Realms. Proceedings of the Black Sea Tourism Forum 'Cultural Tourism - The Future of Bulgaria,' 2010. Rochester, NY: Social Science Research Network.
Osterwalder A, Pigneur Y. 2014. Business Model Generation. Jakarta: PT Elex Media Komputindo.

Pramatatya V, Najib M, Nurrochmat DR. 2015. Pengaruh atmosfer kedai kopi terhadap emosi dan keputusan pembelian ulang. Jurnal Manajemen dan Agribisnis 12(2): 126-136.

Roulin N, Bangerter A. 2013. Extracurricular activities in young applicants' resume: what are the motives behind their involvement?. International Journal of Psychology 48(5):871-880.

Singsomboon T, 2014. Tourism promotion and the use of local wisdom through creative tourism process. International Journal of Business tourism and Applied Sciences 2(2):32-37.

Teparakul O, Sangsnit N. 2013. Creating and maintaining sustainable rural community through. Creative tourism, Experience from Thailand 1-5. 